\title{
DESLOCAMENTOS IMPERIAIS E PERCEPÇÕES DE ALTERIDADE: $O$ CASO DA LITERATURA COLONIAL PORTUGUESA
}

\author{
IMPERIAL DISPLACEMENT AND \\ PERCEPTIONS OF OTHERNESS: PORTUGUESE \\ COLONIAL LITERATURE IN QUESTION
}

Inocência Mata*

\begin{abstract}
RESUMO
As travessias e viagens que permeiam, desde o século XIX, a produção metropolitana sobre a África constituem-se como elementos configuradores da cultura imperial portuguesa e alargam-se ao atlantismo, a base matricial de uma "ideologia" de além-mar (primeiro, ultramarinista; e, já a partir do século XX, da colonialidade), e é uma categoria dos diferentes corpora da produção literária portuguesa no período colonial. Propõe-se, neste ensaio, analisar o deslocamento territorial, produtor de diferentes percepções de alteridade, como um dos mais importantes lugares do património colonial português - a literatura colonial.
\end{abstract}

PALAVRAS-CHAVE: Deslocamento; metrópole e império; alteridade; literatura colonial.

\section{ABSTRACT}

Travel permeates the Portuguese literary metropolitan production on Africa since the $19^{\text {th }}$ century and constitutes one of the most important making elements of the Portuguese imperial culture. This originality extends to Atlanticism, which seems to be the matrix base of an além-mar ideology (first, ultramarinista; and, from the twentieth century, that of "coloniality"), and is a category of different corpora of Portuguese literature in the colonial period. This paper aims at analyzing territorial displacement, producer of different otherness perceptions, as one of the most important loci in the Portuguese colonial heritage - the colonial literature.

KEYWORDS: Displacement; metropolis/empire; otherness; colonial literature. 
Proclamo isto bem alto e bem no auge, na barra do Tejo, de costas para a Europa, braços erguidos, fitando o Atlântico e saudando abstractamente o Infinito. Álvaro de Campos ${ }^{2}$

\section{DE DESLOCAMENTOS E TRAVESSIAS IMPERIAIS: O MAR NA DEFINIÇÃO DA IDENTIDADE PORTUGUESA}

Julgo que a visão marítima de que, n'Os Lusíadas, se impregna o carácter nacional do "peito ilustre lusitano" parece ser a mais emblemática exaltação artística do "espírito heroico" português. É verdade que o poema não inventou a realidade portuguesa de "descobridores de mundos e colonizadores", e sim converteu essa realidade em "Eterno Presente da alma portuguesa" (LOURENÇO, 2014, p. 133). Mas a viagem celebrada - o caminho marítimo para a Índia - parece ser pioneira no funcionamento construtor da comunidade imaginada portuguesa, de que emerge o herói nacional mais transtemporal da história de Portugal, Vasco da Gama. Para Guilherme de Oliveira Martins, o mar é claramente um elemento de definição da identidade portuguesa:

[Nós, os portugueses] muitas vezes não compreendemos suficientemente como esta relação com o maroceano alimenta ilusões e inconstâncias e como nos faz oscilar entre o optimismo e o pessimismo, entre a esperança e o desespero, entre o sonho da grandiosidade e a angústia da pequenez. (MARTINS, 1991, p. 17. Sublinhado do autor)

Com o fazer histórico da nação portuguesa, esse carácter "viajante" foi doravante enformando o imaginário cultural luso que se foi construindo, desde os primórdios da nacionalidade, com as chamadas "reconquistas" e cruzadas além-terras e além-mar (então "apenas" correspondendo ao Norte de África), na altura através de uma (co-)fusão da lenda, da narrativa ficcional e da narrativa histórica, de que Jornada de África (1609), de Jerónimo de Mendonça, pode ser um bom exemplo. É essa categoria de deslocamento territorial que se pretende configuradora da civilização lusa e da sua missão expansionista que, impregnada do labor intelectual pessoano (na esteira dessoutro vieiriano) sobre a visão do mar, confere um carácter original a um dos mais importantes lugares do património colonial português - a literatura colonial: "O mar é português" - diz Leopoldo $\mathrm{Nu}$ nes, em Clarão do império - "Só nós o entendemos, e através dele unimos o grande e vasto Império que descobrimos, civilizámos e engrandecemos, cada vez mais" $(1939$, p. 72$)$.

\section{DE PERCEPÇÕES DE ALTERIDADE: A LITERATURA COLONIAL}

Com efeito, se nos reportarmos, no século XX, à memória dos deslocamentos na produção literária portuguesa no período colonial, esse "heroísmo marítimo" alarga-se no atlantismo ${ }^{3}$, categoria (filosofia?) que será a base matricial de uma "ideologia" de além-mar (primeiro "ultrama- 
rinista" e, depois, já a partir da segunda década, da "colonialidade"), na sua prática literária, e que é uma categoria dos diferentes corpora da produção metropolitana sobre a África. Uma das primeiras reflexões teóricas (e não apenas analíticas) sobre esse corpus é de Augusto dos Santos Abranches, que, numa conferência de 1947 (e publicada em 1949), afirma:

Provável seria, pois, que a actividade colonizadora tivesse também a sua representação, a sua estética peculiar, oferecendo através da realidade criada a sua forma de arte. Seria natural o dar-se como verdadeiro o dístico "literatura colonial" [...] Antes de mais nada, entenda-se que, por "literatura colonial", nos referimos à que pretende contar as reacções do branco perante o meio-ambiente do negro, isto é: a toda essa espécie de descrição mais ou menos ficcionista que nos introduz perante as pessoas imaginariamente vindas de ambientes culturais desenvolvidos, civilizados, para meios-ambientes primitivos. (ABRANCHES, 1949, p. 78)

A literatura colonial constitui uma das representações dessa chamada "vocação atlântica", que se confunde com vocação imperial, nas suas diferentes realizações territoriais (de Angola, da Guiné-Bissau, de Moçambique e de São Tomé e Príncipe): trata-se de um produção que, nos últimos anos, depois de um período em que foi considerada apátrida - um "paradigma submerso", como lhe chamou Francisco Noa (1999, p. 58) -, tem merecido atenção de estudiosos, curiosamente quase todos da área das literaturas africanas, que têm vindo a estudar essa literatura para além do seu circunstancialismo político, na contramão dos protocolos de esquecimento que se estabelece(ra)m na intelligentsia dos países de língua portuguesa, portuguesa mormente, quanto às políticas de divulgação e implementação da cultural imperial. Note-se que Elleke Boehmer, em Colonial an postcolonial literature (1995), traça uma distinção entre "colonial literature" e "colonialist literature", sendo o critério caracterizador desta última uma convergência de autoria (colonizador vale dizer metropolitano e branco) e "o ponto de vista imperialista", que reflete um "ethos colonial" (e os exemplos seriam tanto Robinson Crusoe (1719), de Daniel Defoe, quanto Coração das trevas (1902), de Joseph Conrad, ou Passagem para a Índia (1924), de E. M. Foster, obras que relevam de fases diferentes do império colonial britânico), enquanto a "literatura colonial" seria a textualização de "percepções e experiências coloniais", tanto por metropolitanos quanto por naturais, segundo uma conceptualização que a história da literatura brasileira já consignara. Trata-se, na verdade, de uma distinção capciosa - como o é, também, a formulação "literatura colonial guineense", de Leopoldo $\mathrm{Amado}^{4}$. E neste caso, tanto mais capciosa é essa presunção de nacionalidade literária (guineense, afirma o autor ${ }^{5}$ ) quando se pressupõe que a convivência colonial se pautou por uma "convivência intercultural de séculos" de que resultou uma "cumplicidade cultural de que hoje [nós, guineenses] somos portadores" (AMADO, 2013, p. 8-9). É que essa literatura não releva apenas do contexto colonial, como pretendem Boehmer e Amado: ela faz 
apologia do sistema colonial - e disso resulta que a perspectiva colonialista de Boehmer corresponde à dimensão colonial, enfim, à colonialidade literária, sistematizada em uma dezena de critérios por Manuel Ferreira em $O$ discurso no percurso africano (1989), de que destaco a "celebração colonial" e a "intencionalidade patriótica". Por essa sistematização pretendo recortar, como já fizera em "O texto colonial: uma questão estético-ideológica", o espaço (a natureza) como categoria propulsora de alteridade mas, simultaneamente, como elemento construtor da utopia imperial. Note-se que, nesse contexto,

"Natureza" significa antes de tudo regiões e ecossistemas que não eram dominados pelos europeus, embora incluindo muitas regiões da entidade geográfica conhecida como Europa. (PRATT, 1999, p. 78)

Trata-se, com efeito, de uma produção em que a "continuidade espacial lusa" era um princípio estruturante da estética textual. Diz Sandra I. Sousa, em Ficções do Outro, que "a experiência dos colonos em terras exóticas suscitou a necessidade de exprimir textualmente esses novos mundos através da criação de histórias" (SOUSA, 2014, p. 18-19). Nesse contexto, a viagem era um lugar importante para a construção do conhecimento dessas terras longínquas, sempre actualizado segundo uma lógica cultural imperial na representação dos universos narrados, seja na ficção seja em relatos (portanto, com intenção documental e/ou científica). Essa lógica é visível em títulos de obras - para me reportar aos primórdios dessa literatura - como África misteriosa (1928) ou A derrocada do império vátua (1930), ambos romances de Julião Quintinha e ambos vencedores do Prémio de Literatura Colonial; Pretos e brancos (1926), de Brito Camacho (também premiado no Concurso de Literatura Colonial); Sinfonia bárbara (1935), de Eduardo Correia de Matos; ou, ainda, África: da vida e do amor na selva (1936), de José Augusto da Silva, para citar exemplos de literatura colonial com inspiração de diferentes territórios portugueses. Nesses textos, o africano, entre homem e besta, era perspectivado como elemento da natureza e não como sujeito cultural:

O òbó é um túmulo verde, misterioso. O preto que foge, desce para a floresta como um suicida, que procura liberdade longe da vida numa atitude de desesperada renúncia de quem passa para um outro mundo.

E lá, no òbó, há, na verdade, uma vida diferente.

[...] O preto que fugiu vai viver no òbó o resto da vida. Passa a ser a alma dum outro mundo. É um regresso ao primitivismo feliz. Alimenta-se de banana, de manga, de jaca. A "fruta-pão" fornece-lhe resistência. Dorme sob as folhas lindas das bananeiras num paganismo de Éden perfumado. (Teixeira, 1933, p. 32-35)

Essa conceptualização de natureza continua mesmo em épocas posteriores, mesmo num romance como O branco da Motase (1952), escri- 
to por Manuel Rodrigues Júnior no auge do "colonialismo triunfante", que se estende dos primeiros anos do sistema colonial português até o início das contestações anticoloniais (de acordo com Maria da Conceição Neto, no seu ensaio "Angola no século XX") e que, da violência física e política da colonização, passou à captura do biossocial de forma total e inexorável. Esses textos, embora podendo considerar-se "de viagem" - assim presumiam os sujeitos de enunciação -, não eram relatos de viagem com fins científicos, senão obliquamente por causa do seu cunho etnográfico, que visava o conhecimento do grupo a dominar. Por isso, diferentemente dos relatos de viagens científicos, em que a natureza é "altamente específica e diferenciada" (PRATT, 1999, p. 98), o encontro com a natureza (a geografia, as paisagens e as gentes) converte-se em história só na medida em que ajuda a perceber os meandros das dificuldades encontradas pela personagem, legitimando a autoridade imperial:

Ainda se o nativo consentisse em amanhar a terra alheia... Que era esse o morbo da Província: ter o serviçal de ser recrutado de tão longe, em Cabo Verde e Moçambique.

Estagnado por séculos de calor, bastava ao aborígene estender a mão e colher, lançar a rede e pescar, aparelhar a árvore e erguer a habitação. A natureza fértil nutria-lhe a indolência. (CAJÃO, 1964, p. 50)

É que o código semântico-pragmático desses textos de autoria metropolitana baseava-se na ideologia da continuidade na representação da terra e dos homens, dos espaços e da cultura, de que o enunciado "contos de cá e de lá", para parafrasear Fernando Reis - um relevante escritor da literatura colonial de motivação são-tomense -, dá o mote de descodificação da realização, significando estes deícticos a metrópole e o ultramar, respectivamente. Era preciso inventar um império original, sem colónias, mas com províncias ultramarinas, após o final das campanhas de pacificação (período entendido pelos africanos significativamente como guerras de resistência).

Nesse contexto de uma nova perspectiva do expansionismo colonial, não é, pois, pouco significativo o facto de, recorrentemente, o começo da narrativa (romances, novelas ou contos) se constituir como passos de um percurso ultramarino referenciado como segmento de um mesmo espaço, uno e indivisível, numa realização performativa da portugalidade, ultrapassando-se o olhar viajante da expansão imperial. Afinal, "o que se chama história de um povo, enquanto espelho simplificado do seu passado, é sempre uma idealização" (LOURENÇO, 2014, p. 124).

Desse corpus narrativo, destacam-se, no contexto, as primeiras práticas descritivas - vamos chamar-lhes literárias - que davam notícia da terra (e raramente das gentes como sujeitos culturais e históricos). Eram descrições de efusão lírica (como a cronística e a narrativa testemunhal e histórica) que, evidenciando a visão subjectiva do enunciador, passaram, 
mais tarde, após o período do deslumbramento, a cumprir a primitiva função desse tipo de representação literária: "não apenas a de provocar a faculdade de sonhar (a fantasia) mas também a de apontar para um mundo metafísico, que se situa para além da aparência do real” (PAZ; MONIZ, 1997, p. 93). Poder-se-ia pensar que se trata de uma evolução "natural" da relação do metropolitano com o espaço imperial em que o indivíduo é, mais do que naturalizado, biologizado: com efeito, "quanto mais selvagem a natureza, mais selvagem a cultura” (PRATT, 1999, p. 231). Nesse âmbito se inserem crónicas, apontamentos e roteiros de viagem - que compõem a segunda modalidade do Concurso de Literatura, nesta sua segunda fase (a partir de 1932) ${ }^{6}$, de que são exemplos obras premiadas tais como Roteiro de África (1936), de José Osório de Oliveira; África: da vida e do amor na selva (1936), de José Augusto da Silva; Clarão do império (1939), de Leopoldo Nunes; Ao sol do império (1938), de Fernando de Pamplona, significativamente com o subtítulo "crónicas africanas" (sendo estas duas últimas narrativas motivadas pela viagem do então presidente português, o marechal António Óscar de Fragoso Carmona, a São Tomé e a Luanda), Padrão de soberania (1939), de José Augusto, para além de textos etnográficos, como Babel negra: etnografia, arte e cultura dos indígenas da Guiné (1935), de Landerset Simões, com prefácio de Norton de Matos (um estratega da política colonial portuguesa), obra que Leopoldo Amado considera "um dos estudos etno-antropológicos mais cientificamente elaborados sobre a Guiné" (AMADO, 2013, p. 17). Aquelas categorias genológicas (desde apontamentos etnográficos e históricos, viagens e relatos de aventuras à produção ficcional) são importantes porque se impõem no horizonte configurador do imaginário colonial português, no confronto com o espaço estrangeiro, a partir do qual emerge a conflitiva alteridade, que é o nódulo fundador da literatura colonial. E esse primeiro confronto começa no/com o espaço, que se constitui como o outro, pela estranheza e intensa diferença, sobressaindo-se muitas vezes a admiração e a edenização como categorias subjacentes nessa observação. Essa primeira relação de alteridade do viajante (metropolitano), manifesta no enfrentamento do sujeito da escrita com a magnificência do espaço (geografia, natureza e gentes), avaliza, não obstante, um objecto tangível, embora sensível, cuja apreensão e inteligibilidade se processam ora por via espiritual (como no conto "Ossobó”, de Ruy Cinatti) e ideológica (a que não está ausente a dimensão económica) ora pela via científica, mas quase sempre nos contornos de idealização, como neste trecho de uma descrição de Castro Soromenho (1936) sobre uma viagem à colónia de São Tomé e Príncipe:

Príncipe - calvário de homens e de eternas belezas. Os homens que primeiro foram fecundar o teu ventre ubérrimo morreram doidos de febres e deslumbrados com a tua verdura exuberante. [...]

Morreram felizes porque até ao momento da abalada só viram esplendor, riquezas de lenda, toda a sua louca ambição realizada... 
E outros homens vieram, sem temer os infortúnios e a própria morte, e tanto sonho trouxeram na alma que tu te rendeste à sua glória em oferenda a Portugal. (SOROMENHO, 1968, p. 131-132)

Em todo o caso, decorrente dessa relação de alteridade - mais ainda, de intensa estrangeiridade, em que o espaço se constitui como locus horrendus - que emerge do primeiro encontro, diferentes configurações estético-ideológicas podem ser lidas no quadro de uma regionalidade literária portuguesa, e elas passarão a integrar a diferença entre a discursividade imperial/ultramarina-colonial e a africana. É essa diferença que actualiza os modos de representação, que não se distinguem apenas por um paisagismo mais ou menos nativista, ou pelo gosto pela cor local, ou pelo fato de a autoria ser de africanos, de naturais daqueles espaços, no limiar da nacionalização literária - até porque, no auge dessa produção (apontamentos narrativos, crónicas, memórias, testemunhos, itinerários, roteiros, diários e relações de viagem), ainda não se podia considerar sistematizadas as vertentes do cânone da africanidade literária. Para trás ficaram narrativas que foram (re)editando um percurso que se aproxima das canónicas narrativas de viagem no espaço imperial português, tanto em paralelo com a literatura colonial quanto em contraposição a uma literatura africana de "expressão portuguesa", como então se designava. Vale, a propósito, para lembrar o embate entre os dois corpora, recorrer à afirmação de Amândio César - ele próprio um dos mais emblemáticos críticos da literatura colonial -, num "ensaio colonial" de 1967 sobre a produção de autoria africana:

A 'expressão portuguesa' na literatura africana é um eufemismo criado e divulgado por Mário de Andrade e a sua definição vem bem expressa no ensaio datado de Abril de 1953. [...] Não há, pois, uma arte ou literatura negra de expressão portuguesa [mas um] Ultramar literário, cujo conteúdo abrange todo o território que vai do Minho até Timor. (CÉSAR, 1967, p. 132-133)

Até então, isto é, até o momento dos primeiros sinais de construção dos sistemas nacionais das literaturas africanas - pioneiramente com o intencional trabalho levado a efeito pelo sector editorial da Casa dos Estudantes do Império, na coleção "Autores Ultramarinos", e pelas antologias poéticas, a partir dos anos 50 do século XX -, esses outros textos destacavam-se pela tónica no louvor imperial e na informação conciliada com o tom de reportagem e a divulgação territorial do império. E se "a viagem, enquanto meio de conhecer o exótico, o estranho, ou de procurar a evasão do quotidiano, recorrente nos textos da literatura colonial, é o meio de aceder a um império maravilhoso, se bem que emerso num oceano de perigos desconhecidos" (LARANJEIRA, 1998, p. 72), não é despiciendo o facto de Julião Quintinha afirmar, no prólogo da sua Novela africana (1933), que o povo português "teve sempre, os olhos cheios de mar, e a alma sedenta de desconhecido" (1933, p. 8). 
Julião Quintinha é um exemplo do viajante “missionário” da empresa colonial, tendo realizado inúmeras viagens ao continente africano e publicado reportagens sobre as terras e as gentes e vencido sucessivamente prémios da literatura colonial com obras de modalidades diferentes. Na sua obra, o político chegava a suplantar o pendor estético, tal era o empenho patriótico que o autor punha na prática narrativa de busca edificante do espaço imperial. José Augusto afirmaria, anos depois, em Padrão de soberania, acerca dessa apetência para a viagem como configuradora da "civilização portuguesa": O mesmo mar que viu reflectir-se nas águas as cruzes e as signas de Portugal, o mesmo que foi fendido pelas quilhas das Naus, que a Fé e a Ousadia conduziam a porto inesperado abrindo rota desconhecida... Porque o mar que servia para separar continentes foi o traço de união (AUGUSTO, 1939, p. 14).

Nessa época esses textos nem se propunham a se substrair à circunstancialidade ideológica, marcando a sua intencionalidade pelo registo da dimensão epopeica do civilizador, que se desloca da metrópole com o intuito de dominar uma terra perigosamente bela. É por isso que, nesses textos, a viagem aparece, quase sempre, como dos primeiros eventos diegéticos, numa temerária conciliação entre a promessa do locus amœnus e a manifestação do locus horrendus: "calvário de homens e de eternas belezas" (SOROMENHO, 1968, p. 132).

Com efeito, nesse primeiro evento diegético há quase sempre um jovem português que, por qualquer motivo (sentimental, familiar, político, financeiro ou outro), decide viajar para a África; ele é pobre mas trabalhador, honesto, diligente, generoso, patriota e, quando chega ao novo espaço, não possui nada, tudo lhe é hostil, desde a geografia às gentes (isto é, o que representaria a cultura local). Todavia, persistente como é, consegue vencer, impor-se e integrar-se, e ganhar a simpatia da população local, que, embora claramente adjuvante, é o beneficiário desse esforço.

Na literatura colonial, a viagem é um elemento muito importante na trama narrativa porque revela um aspecto definidor: a alteridade em relação àquele mundo (geografia, natureza e gentes, enfim, elementos fundamentais de identidade). Com efeito, a personagem metropolitana não pertence àquele espaço (físico e cultural). A construção épica da personagem insinua-se, então, porque "o indivíduo épico, o herói de romance, nasce desta alteridade do mundo exterior" (LUKÁCS, s/d, p. 66). Assim, o carácter dessa personagem vai-se revestindo de uma dimensão sacrificial que, acentuada pela saudade da terra e da família e pelas dificuldades reais de sobrevivência (o clima, a dureza do quotidiano advinda da estranheza do espaço sociocultural), converge para a sua heroicização. É assim que essas narrativas de deslocamento constroem uma epopeia do colonizador, a partir da sua estrutura iniciática (saída da terra $\rightarrow$ dificuldades $\rightarrow$ vitória/ recompensa, que é a conquista da terra e o cumprimento da missão civilizadora). Portanto, esse percurso aponta para a missão civilizadora do viajante, na medida em que o recém-chegado, que a princípio se confronta 
com um espaço hostil (aquele tipo de alimentação, aquele clima, aqueles hábitos, usos e costumes), torna-se, no final, um defensor do mundo africano, como na novela "Nga-Sakirila" (1936), de Viana de Almeida - e nisso reside a sua entrada na "série épica de dificuldades, desafios e encontros com o imprevisível (PRATT, 1999, p. 138). Além de que, através da viagem que estrutura uma unidade temática na/da estória, gera-se uma unidade geográfica de Portugal, realizando-se a celebrada pluricontinentalidade do império colonial português. É que esse metropolitano, já herói desde a sua partida, vai continuar o espaço português - também através da miscigenação: não raro, ele tem o apoio de uma mulher local (referida da historiografia colonial como nativa) e com ela tem filhos mulatos, actualizando a multirracialidade e a mestiçagem, outro critério da originalidade imperial portuguesa, marcada pelo mito da criação de uma civilização lusotropical. Mesmo quando esse herói não regressa - como são os casos do "colono" de Tomaz Vieira da Cruz, Pedro da Maia em Muende, Rodrigues Junior ou Álvaro em Fortunas d’Africa 10, de M. Récio e Domingos S. de Freitas -, a derrota (morte ou aniquilamento moral) faz dele vítima, acentuando a positividade do império e exponenciando o estatuto do herói colonial.

\section{UMA ABERTURA PARA A DIFERENÇA, COM "OLHOS IMPERIAIS": "COLONO", DE TOMAZ VIEIRA DA CRUZ}

Um exemplo desse esquema ideológico da narrativa é, pois, "Colono", poema narrativo de Tomás Vieira da Silva - o "poeta da musa mulata", português radicado em Angola, onde viveu e escreveu toda a sua obra (Quissange - saudade negra, 1932; Tatuagem, 1941; Cazumbi, 1950; Cinco Poesias da África, 1950; Poesia angolana, 1961; Quissange, 1971). Trata-se de um poema (que será transcrito na íntegra) em que o ultranacionalismo imperial português se conjuga com a imagética mítica de uma África a descobrir:

\section{Colono}

A terra que lhe cobriu o rosto

E lhe beijou o último sorriso,

Foi ele o primeiro homem que a pisou!

Ele venceu a terra que o venceu.

Ele construiu a casa onde viveu ...

Ele desbravou a terra heroicamente,

Sem um temor, sem uma hesitação,

- terra fecunda que lhe deu o pão

E lhe floriu a mesa de tacula ...

Mas quando olhava a imagem pequenina

- Senhora da Boa Viagem -

Que a mãe lhe pôs ao peito à hora da partida,

O Homem forte chorava...

Foi arquitecto e foi também pintor,

porque pintou de verde a sua esperança... 
Esculpiu na própria alma um sonho enorme, por isso foi também grande escultor!

Foi genial artista e mal sabia ler!

O que aprendeu foi Deus que o ensinou, lá na floresta virgem, imensa catedral, onde tanta vez ajoelhou!

Viveu a vida inteira olhando o céu, a contar as noites da lua nova à lua cheia.

E o sol do meio dia lhe queimou a pele, o corpo todo e até a alma pura.

Foi médico na doença que o matou, ao homem ignorado e primitivo que derrubou bravios matagais e junto deles caiu como caem árvores sacrificadas à abundância dos frutos que criaram ...

E a primeira mulher que amou e quis foi sua inteiramente ...

E era negra e bela, tal o seu destino!

E ela o acompanhou como a mais funda raiz acompanha a flor de altura que perfuma as mãos cruéis de quem a arrancou.

Foi o primeiro em tudo, na dor e no Amor, na honra e na Saudade porque nunca mais voltou ...

(Cazumbi, 1950)

Ainda que este mesmo poema possa ser considerado antecessor à atitude de assumida valorização da terra angolana que iria eclodir nos anos 40/50, ele é emblemático na transformação da relação de alteridade em relação de posse que a condição de branco colonizador proporciona. O processo de adaptação do "colono"7 ao espaço revela característica do que Mary Louise Pratt designou como "anticonquista", referindo "estratégias de representação por meio das quais os agentes burgueses europeus procuram assegurar sua inocência ao mesmo tempo em que asseguram a hegemonia européia" (1999, p. 32). Com efeito, toda a narrativa se constrói como se de um (simples) imigrante se tratasse, descrito com semas que apontam para a construção de um novo mundo: pioneiro, arquitecto, escultor, pintor, desbravador - enfim, uma figura inocente em relação à exploração colonial, e com uma moral irreprensível (o amor à mãe e a lealdade conjugal). A sua acção tem como beneficiário "o homem ignorado e primitivo". Vale lembrar, neste contexto, Eduardo Lourenço, que, num ensaio de 1985, afirma 
que "o colonialismo é um espelho deformante onde todas as motivações suspeitas se podem branquear e vice-versa" (2014, p. 123).

Esse é claramente um caso de nítida contaminação épica do personagem, que, saído da sua terra pobre e analfabeto, vence o espaço, conquista-o e transforma-o em terra sua, portuguesa - sucumbindo apenas face ao sentido primordial da tradição religiosa:

\author{
Mas quando olhava a imagem pequenina \\ - Senhora da Boa Viagem - \\ Que a mãe lhe pôs ao peito à hora da partida, \\ O Homem forte chorava...
}

Nesse processo, o herói - claramente com "olhos imperiais" pela posse que faz da terra - pode ter, porém, um adjuvante que é, simultaneamente, destinatário da empresa da "civilização": as personagens negras, nunca sujeitos, apenas parte integrante do espaço/ natureza, o que legitima a autoridade da posse da terra, acentuada pelo facto de o protagonista se tratar de alguém que veio de longe em condições precárias.

Esse poema, e a obra de Tomaz Vieira da Cruz em geral, tem um efeito de leitura peculiar: enquanto nas obras "clássicas" da colonialidade literária a natureza do efeito de leitura se aproxima do pathos (de que resulta uma reacção de incomodidade, como no conto "A carta", de Maria Archer", em que o homem negro é referido como uma criatura de transição entre a animalidade e a humanidade, uma "criança grande"), no poema "Colono" a base ideológica, embora em diálogo intertextual com outras formas da discursividade colonial, estabelece uma intertextualidade exoliterária mais subtil, porém de efeito ético: o leitor não se apercebe da ideologia imperial subjacente porque o seu código moral e ético se apresenta como decorrente de critérios da condição humana: a viagem do "colono" acaba por ler-se não como empresa de colonização, mas como emigração (um emigrante, despossuído e analfabeto porém trabalhador, que deixa na terra a mãe, em quem pensa constantemente, e se aventura por um mundo inóspito e desconhecido: "Foi ele o primeiro homem que a pisou!"). E essa intertextualidade colonial não se limita à criação dos mesmos actantes, funcionando em binómios (colono/trabalhador, mulher negra/adjuvante, espaço hostil/ pioneirismo, etc.), antes releva da dimensão pragmática e programática dessa ideologia na sua vertente expansionista.

Ele venceu a terra que o venceu.

Ele construiu a casa onde viveu ...

Ele desbravou a terra heroicamente,

Sem um temor, sem uma hesitação,

- terra fecunda que lhe deu o pão

E lhe floriu a mesa de tacula .......]

Foi arquitecto e foi também pintor,

porque pintou de verde a sua esperança ...

Esculpiu na própria alma um sonho enorme, por isso foi também grande escultor! 


\section{BREVES CONSIDERAÇÕES FINAIS: DA LITERATURA COLONIAL COMO LITERATURA DE VIAGEM}

As obras que constituem o corpus da produção literária de motivação imperial, transitando entre a literatura de viagem e a literatura colonial, partilham um importante critério de caracterização: ao mesmo tempo que reforçam as imagens de lugares de origem metropolitana, buscam outros espaços em que a "vocação atlântica" portuguesa se realiza, como forma de abertura para a diferença e para o outro (espaço e gentes) - ainda que disso resulte, sempre, no apoderamento desse outro. Esse corpus constrói, em cada segmento territorial (perfeitamente identificável - daí o equívoco de se falar de "literatura colonial guineense"), uma epopeia da colonização, com o seu corolário de civilização e evangelização do "gentio", em que o enunciador (personagens metropolitanas ou narradores de reportagens e relatórios) faz um percurso iniciático de adaptação ao novo espaço. Uma dessas personagens resume da seguinte maneira a caracterização d'"esta rapaziada [metropolitana] que vem para o ultramar": "Até aos cinco anos são ultramarinos; dos cinco aos vinte, são ultramarotos, e depois são ultramalandros" (REIS, 1960, p. 146).

Não obstante, esse discurso com dimensão apologética da presença portuguesa em África revela um espírito de recusa, inconsciente que seja, de procura de exotismo, e enquadra-se perfeitamente na recepção geopolítica do binómio nacional/regional, com base na "pluricontinentalidade cultural", o que parece concordante com a linha (ideo)lógica da textologia de viagem e/ou colonial.

E porque "as potencialidades do futuro eurocolonial são justificadas com base nas ausências e lacunas da vida africana no presente" (PRATT, 1999, p. 115), o viajante - aquele que se deslocou da sua longínqua terra para um mundo completamente diferente - apresenta-se como um aventureiro, e o espaço/tempo textual ganha a modalidade de narrativa de experiências pessoais. Simultaneamente, essa experiência narrada legitima também o desenho do retrato etnográfico que permite o (re)conhecimento do outro espaço imperial.

Macau, Março de 2016

\section{REFERÊNCIAS BIBLIOGRÁFICAS}

ABRANCHES, Augusto do Santos. Sobre "Literatura colonial". In: Seara Nova (Lisboa), no 1099- 1120 (Lisboa), Janeiro a Junho de 1949.

ALMEIDA, Viana de. Nga-Sakirila. In: Maiá Poçón (contos). Lisboa: Edições Momento, 1937.

AMADO, Amado. A literatura colonial guineense. In: Guineidade \& africanidade: estudos, crónicas, ensaios e outros textos. Lisboa: Edições Vieira da Silva, 2013, p. 7-20. 
AUGUSTO, José. Padrão de soberania. Lisboa: Agência Geral das Colónias, 1939.

BOEHMER, Elleke. Colonial and postcolonial literature. Oxford: Oxford University Press, 1995.

CÉSAR, Amândio. Parágrafos de literatura ultramarina. Braga: Sociedade de Expansão Cultural, 1967.

CASTRO SOROMENHO. Ilha do Príncipe. In: CÉSAR, Amândio. Presença de S. Tomé e Príncipe na moderna cultura portuguesa. S. Tomé, 1968 [publicado primeiramente em O Mundo Português, vol. 3, n 30, 1936].

GARCIA, José Luís Lima. A literatura de propaganda colonial no Portugal contemporâneo vintecentista. ln: Estudos do século $X X, \mathrm{n}^{\circ}$ 8, 2008, p. 305-315.

FERREIRA, Manuel. Uma perspectiva do romance colonial vs. literaturas africanas. In: $O$ discurso no percurso africano: contribuição para uma estética africana. Lisboa: Editora Plátano, 1989, p. 231-259.

LARANJEIRA, José Luís Pires. A literatura colonial portuguesa. In: África: Revista do Centro de Estudos Africanos. USP, S. Paulo, $\mathrm{n}^{\text {os }} 20-21$, 1997/1998, p. 71-77.

LOURENÇO, Eduardo. Retrato póstumo do nosso colonialismo inocente I. In: Do colonialismo como nosso impensado. Organização de Margarida Calafate Ribeiro e Roberto Vecchi. Lisboa: Gradiva, 2014.

LUKÁCS, Georg. Teoria do romance. Lisboa: Editorial Presença, s/d.

MARTINS, Guilherme de Oliveira. Mar português, porto de chegada e de partida. In: JL: Jornal de Letras, Artes e Ideias. Lisboa, 13 ago. 1991, p. 17.

MATA, Inocência. O texto colonial: uma questão estético-ideológica. In: Mensagem. Luanda, $\mathrm{n}^{\circ} 4,1989$, p. 32-39. Incluído em: Literatura angolana: silêncios e falas de uma voz inquieta. Lisboa: Mar Além, 2001, p. 48-54.

NETO, Maria da Conceição. Angola no século XX (até 1974). In: ALEXANDRE, Valentim (Coord.). O império africano: séculos XIX e XX. Lisboa: Edições Colibri/Instituto de História Contemporânea da FCSH-UNL, 2000.

NOA, Francisco. Literatura colonial em Moçambique: o paradigma submerso. In: Via Atlântica - revista do Programa de Pós-Graduação de Estudos Comparados de Literaturas de Língua Portuguesa da Faculdade de Filosofia, Letras e Ciências Humanas (USP), nº. 3, dez. 1999, p. 58-68.

NUNES, Leopoldo. Clarão do império (comentário à viagem presidencial às províncias de S. Tomé e Príncipe em Julho e Agosto de 1938). Lisboa: [s.n.], 1939.

PAZ, Olegário; MONIZ, Antônio. Dicionário breve dos termos literários. Lisboa: Editorial Presença, 1997.

PRATT, Mary-Louise. Os olhos do império: relatos de viagens e transculturação. Bauru: EdUSC (Editora da Universidade do Sagrado Coração), 1999. 
QUINTINHA, Julião. Novela africana. Lisboa, Casa Editora Nunes, 1933.

RÉCIO, Manuel; FREITAS, Domingos S. de. Fortunas d'Africa (novela). Lisboa: Casa Ventura Abrantes, 1933.

REIS, Fernando. Roça (romance), Lisboa: Sociedade de Expansão Cultural, 1965.

RODRIGUES JÚNIOR. Muende (romance). Lourenço Marques: África Editora, 1960.

SOUSA, Sandra I. Ficções do Outro: império, raça e subjectividade no Moçambique colonial. Lisboa: LusoSofia Press, 2014.

TEIXEIRA, Luiz. Na roda do batuque. Lisboa: Livraria Bertrand, 1933.

Recebido para publicação em 28/03/2016

Aprovado em 23/05/2016

\section{NOTAS}

* Doutora em Letras pela Universidade de Lisboa e com pós-doutoramento em Estudos Pós-coloniais (Postcolonial Studies, Identity, Ethnicity, and Globalization, pela Universidade de Califórnia, Berkeley), é professora da Faculdade de Letras da Universidade de Lisboa na área de Literaturas, Artes e Culturas. É atualmente vice-directora do Departamento de Português da Universidade de Macau, onde exerce como professora associada com uma licença especial, tendo trabalhos publicados na área de literaturas em português, sobretudo literaturas africanas, e dos estudos pós-coloniais.

2 Ultimatum. In: Portugal Futurista, no 1. Lisboa: 1917. (Ed. fac-símile. Lisboa: Contexto, 1981).

3 É óbvio que o termo é aqui utilizado não como doutrina "ocidental", que, partindo da ideologia estruturadora da OTAN (Organização do Tratado do Atlântico Norte), traduz a política de cooperação, dita defensiva, entre os países europeus e os Estados Unidos, mas como ideologia de que se diz imbuir a civilização portuguesa e que é a sua "vocação atlântica".

4 Primeiramente publicado em Soronda: revista de estudos guineenses (Bissau), n 9, jan. 1990 (p. 73- 93) e depois na Revista ICALP (Lisboa), vol. 20 e 21, julho-outubro de 1990 (p. 160-178), este artigo integra a colectânea Guineidade \& africanidade (Lisboa: Edições Vieira da Silva, 2013), a partir da qual são feitas as citações.

5 Trata-se, na verdade, de uma pressuposição ambígua, pois no final do ensaio o autor opõe "literatura colonial" a "literatura nacional, entendendo-se esta como literatura guineense: "É exactamente tendo em conta este postulado [o "assunto"] que atribuímos à Literatura Colonial uma importância particular no que concerne ao seu relacionamento com a Literatura Nacional" (AMADO, 2013, p. 20).

6 Note-se que "A grande alteração no regulamento desta segunda fase foi a criação de três categorias de prémios, de acordo com os géneros que se pretendiam realçar e promover. Assim, as modalidades a concurso passaram a ser as seguintes: 1. a categoria: inseridos no campo do conto, ficção, narrativa, novela, relato de aventuras, romance; 2 . a categoria: obras sobre biografias, etnografia, história e viagens; 3 . a categoria: todo o tipo de obras que se integrassem na "literatura científica”' (GARCIA, 2008, p. 209).

7 Interessante é a palavra inglesa para colono - settler: alguém que migra para um novo espaço, não existindo, etimologicamente, nesta definição uma semântica de dominação.

8 Maria Archer. A carta. In: CÉSAR, Amândio. Contos portugueses do ultramar. Porto: Portucalense, 1969. 